\title{
PEMETAAN EFEK SPASIAL KEMISKINAN SELURUH KABUPATEN DI INDONESIA
}

\author{
Sarah Nita Hasibuan ${ }^{1}$, Mutia Harum Hasibuan² \\ Komite Pemantauan Pelaksanaan Otonomi Daerah', Fakultas Ekonomi dan Bisnis, \\ Universitas Negeri Medan² \\ Jl. Kuningan Mulia, Setia Budi, Jakarta Selatan', Jl. Willem Iskandar, Medan Tembung, Medan \\ email: hasibuannita091@gmail.com ${ }^{1}$ mutiaharum04@gmail.com ${ }^{2}$
}

\begin{abstract}
Poverty is one of the obstacles to the difficulty of the country development. Poverty causes a decrease of human resources quality, inability to access education, health, good nutrition which results in productivity degradation. The purpose of this study are to analyze the pattern of spatial poverty all regencies in Indonesia using the Moran's Index and looks at the local spatial distribution of poverty using the Local Indicator of Spatial Autocorrelation (LISA) approach. This study uses the data period in 2019. The results of this study show that pockets of poverty in Indonesia are mostly located in the provinces of Papua, West Papua and East Nusa Tenggara. The regencies with the lowest poverty are found in the regencies of Bali and South Kalimantan Provinces. Moran's Test showed a positive autocorrelation of 0.474259 which indicates a general spatial autocorrelation across all regency in Indonesia with a clusted pattern. The LISA test showed poverty level of the population was clustered into four groups, namely: 50 regencies that were in the high poverty regencies surrounded by high poverty (high-high), 69 regencies in low poverty criteria surrounded by low poverty regencies (low-low), 12 regencies in the low poverty, surrounded by high poverty (low-high) and 5 high poverty regencies surrounded by low poverty (high-low). Thus, this study proves that poverty reduction must be based on the uniqueness and characteristics of each region.
\end{abstract}

Keywords: Moran Index, mapping cluster, poverty, spatial autocorrelation

\begin{abstract}
ABSTRAK
Kemiskinan menjadi salah satu penghambat sulitnya suatu daerah/negara untuk maju. Kemiskinan menyebabkan menurunnya kualitas sumberdaya manusia, akibat ketidakmampuan mengakses pendidikan, kesehatan, nutrisi yang baik yang berimbas pada produktivitas yang melemah. Studi ini bertujuan untuk menganalisis pola sebaran kemiskinan seluruh kabupaten di Indonesia dengan memakai metode Moran's Index. Selain itu studi ini juga melihat sebaran spasial kemiskinan secara lokal di setiap kabupaten dengan pendekatan Local Indicator of Spatial Autocorrelation (LISA). Adapun periode data yang digunakan adalah tahun 2019. Hasil studi mengemukakan kantongkantong kemiskinan di Indonesia sebagian besar terletak di Provinsi Papua, Papua Barat dan Nusa Tenggara Timur. Kabupaten dengan kemiskinan terendah terdapat di kabupaten Provinsi Bali dan Kalimantan Selatan. Hasil perhitungan Uji Moran terdapat autokorelasi positif sebesar 0,474259 yang menunjukkan adanya keterkaitan spasial secara umum di seluruh kabupaten di Indonesia dengan pola yang menggerombol (clustred). Sementara hasil uji LISA memetakan tingkat kemiskinan penduduk dalam empat kelompok, yakni: terdapat 50 Kabupaten yang berada pada kriteria kabupaten dengan kemiskinan tinggi dikelilingi kabupaten kemiskinan tinggi (high-high), 69 kabupaten yang masuk dalam kriteria kemiskinan rendah dikelilingi kabupaten kemiskinan rendah (low-low), 12 kabupaten pada kriteria kemiskinan rendah, dikelilingi kabupaten kemiskinan tinggi (low-high) dan 5 kabupaten kemiskinan tinggi dikelilingi kabupaten kemiskinan rendah (high-low). Perbedaan tingkat kemiskinan menunjukkan penanganan/penuntasan kemiskinan tidak dapat diseragamkan setiap daerah.
\end{abstract}


Kata kunci: Autokorelasi spasial, Indeks Moran, pemetaan wilayah, tingkat kemiskinan

\section{PENDAHULUAN}

Sebagai suatu negara dengan tingkat populasi yang besar dan beragam (heterogen), penentuan daerah dan sasaran yang tepat dalam program peningkatankesejahteraan merupakan hal yang penting dan krusial. Kemiskinan merupakan tingkatankehidupan yang berada di bawah standar kebutuhan minimum. BPS mengemukakan garis kemiskinan pada tahun 2020 adalah 454.652/kapita/bulan. Jika mengacu pada standar Bank dunia kriteria kemiskinan diusulkan dua hal, yang pertama USD1 perkapita perhari yang merupakan ukuran kemiskinan absolut dan kedua, mencapai USD2 per kapita perhari. Apabila menggunakan ukuran kedua maka tingkat kemiskinan di Indonesiamencapai 52 persen di bawah garis kemiskinan (Damanhuri, 2010). Tingkat kemiskinan yang tinggi membuat suatu negara sulit berkembang dan memperlambat pertumbuhan ekonomi negara. (Todaro \& Smith, 2011) mengemukakan paling tidak terdapat limaalasan mengapa kebijakan harus berfokus pada penurunan kemiskinan, pertama: kemiskinan yang tinggi akan menciptakan masyarakat sulit mendapatkan pinjaman, tidak mampu membiayai pendidikan anak-anak mereka; kedua, orang kaya yang jatuh miskin umumnya tidak menghemat, tidak menabung dan tidak investasi; ketiga, tingkat pendapatan dan standar hidup rendah berdampak pada buruknya kesehatan, nutrisi dan menurunkan produktivitas; keempat, meningkatnya pendapatan penduduk miskin merangsang pertumbuhan produk lokal untuk kebutuhan hidup sehari-hari dan teraknir pengurangan kemiskinan dapat mendorong perluasan perekonomian yang sehat. Fakta problematiknya, tingkat kemikinan di Indonesia masih tinggi, meskipun terdapat penurunan di setiap tahunnya. Data BPS menunjukkan terdapat peningkatan kemiskinan baik di perkotaan maupun di perdesaan tahun 2020. Jumlah penduduk miskin perkotaan menjadi 11,16 juta orang sementara jumlah penduduk miskin perdesaan naik menjadi 14,93 juta penduduk (Maret 2020) lihat Tabel 1.

Tabel 1. Perkembangan Tingkat Kemiskinan di Wilayah Perkotaan dan Perdesaan Tahun 2015-2020 (Persen)

\begin{tabular}{rrrr}
\hline \multicolumn{1}{c}{ Tahun } & Wilayah Perkotaan & Wilayah Perdesaan & Total \\
\hline 2015 & 8,29 & 14,21 & 22,50 \\
2016 & 7,79 & 14,11 & 21,90 \\
2017 & 7,72 & 13,93 & 20,65 \\
2018 & 7,02 & 13,20 & 20,22 \\
2019 & 6,69 & 12,60 & 19,34 \\
2020 & 7,38 & 12,82 & 20,20 \\
\hline
\end{tabular}

Sumber: BPS, 2021

Tabel 1 menunjukkan kemiskinan di perkotaan dan perdesaan cenderung mengalami penurunan setiap tahunnya, kecuali di tahun 2020 terjadi peningkatan. Kondisi ini diakibatkan terjadinya pandemi Covid-19 yang melanda dunia, menyebabkan perputaran ekonomi melemah, pembatasan sosial berskala besar, dan PHK yang tinggi. Jika diperhatikan lebih teliti peningkatan kemiskinan di perdesaan tidak terlalu tinggi, dibandingkan daerah perkotaan. Kenaikan kemiskinan di perkotaan mencapai 0,69 persen sedangkan di perdesaan sebesar 0,18 persen tahun 2020. Kondisi ini disebabkan 


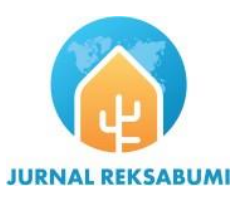

JournalHomepage: http://jurnal.ut.ac.id/reksabumi
P-ISSN: 0000-0000 dan E-ISSN: 0000-0000

Volume 1 Nomor 1, Bulan Tahun, 01-22 https://doi.org/10.33830/Reksabumi.v1i1.2058.2022

karakteristik perdesaan yang merupakan pertanian dan sebagian besar masyarakatnya bekerja sebagai petani dan buruh tani. BPS menyebutkan dikala sektor-sektor lain mengalami kontraksi, hanya sektor pertanianlah yang tumbuh mencapai 15,24 persen pada kuartal kedua. Berbeda halnya dengan perkotaan yang merupakan wilayah industri dan jasa, sehingga pandemi Covid menggungcang keras perekonomian di perkotaan.

Fauzi (2020) menyebutkan dampak pandemi Covid paling parah dirasakan penduduk berpenghasilan rendah. Sebagaimana hasil laporan BPS menyebutkan 70 persen masyarakat berpenghasilan rendah mengalami penurunan pendapatan, sementara masyarakat bepenghasilan rendah mengaku 30 persen mengalami penurunanpendapatan. Kondisi inilah yang menjadi pemicu lemahnya pertumbuhan ekonomi bahkan mengalami resesi selama 3 kuartal berturut-turut. Akibatnya perekonomian Indonesia baik diperdesaan maupun perkotaan mengalami perlambatan (Indayani \& Hartono, 2020).Peningkatan kemiskinan ini berdampak pada kenaikan Gini Ratio. Gini Ratio perkotaan perkotaan naik 0,001 poin dibanding tahun 2019 menjadi 0,393. Sementara Gini Ratio perdesaan meningkat sebesar 0,002 poin menjadi 0,317 poin di tahun 2020 (BPS, 2021). Hal ini karena terjadi penurunan pendapatan seluruh lapisan masyarakat khususnya bagi masyarakat yang tidak bekerja di sektor formal. Disisi lain, pandemi Covid juga telah membuat tersendatnya program-program pemerintah yangsudah direncanakan di tahun sebelumnya (refocusing program). Untuk itu, perlu eksplorasi potensi daerah sebagai sumber-sumber pertumbuhan baru, mengingat kesenjangan dan kemiskinan desa/kota masih tinggi. Pengoptimalan potensi perdesaan pun perlu digerakkan sehingga menjadi alternatif tempat/wadah yang menarik untuk ditinggali dan memperoleh kehidupan yang layak (UMKM, agroindustri, ekowisata, dan lain-lainnya).

Ketersediaan sarana pendukung daerah pun harus dibangun agar dapat mendukung lancarnya aktivitas ekonomi (irigasi, sarana dan prasarana transportasi, listrik, internet, telepon, fasilitas pendidikan dan kesehatan) pasca pandemi. Masykuroh \&Rudiarto, (2016) mengemukakan pembangunan yang pesat menumbuhkan sub pusat baru, menumbuhkan sarana dan prasarana, aksesibilitas yang lengkap sehingga memudahkan masyarakat memenuhi kebutuhan hidupnya. Terdapat beberapa penyebab sulitnya menangani kemiskinan di Indonesia di antaranya: lemahnya institusi pengelolaan program pengentasan kemiskinan (belum ada sinergitas antarprogram pusat dan daerah dalam pengentasan kemiskinan, lemahnya basis data keluarga miskin yang digunakan sebagai penerima manfaat program anti kemiskinan (ditandai penerima bantuan untuk masyarakat miskin kurang tepat sasaran), dukungan anggaran yang masih minim. Pemberdayaan ekonomi masyarakat melalui UMKM dan sektor informal lainnya menjadi soko guru untuk menuntaskan masalah-masalah kemiskinan ini, sebab lebih dari 90 persen perekonomian Indonesia di sumbang sektor UMKM. Sebagaimana yangdikemukakan (Gunartin, 2017), UMKM merupakan faktor penting dalam menumbuhkan ekonomi daerah dan negara melalui penyerapan tenaga kerja untuk pengurangan pengangguran dan kemiskinan. Irawandi, (2018) mengemukakan, selain fokus pada program penuntasan kemiskinan dan kesenjangan, hal yang tidak kalah penting adalah memerhatikan aspek spasialnya. Pendapat ini pun diperkuat oleh Nashwari et al., (2016); Rustiadi et al. (2009) dimana aspek spasial memberikan pengaruh terhadap penyebaran kemiskinan. Kegagalan program penanggulangan kemiskinan disebabkan adanyapenyeragaman kebijakan pada masingmasing daerah. Variasi dan Karakteristik wilayah 
yang berbeda mengharuskan penanggulangan kemiskinan pun berbeda. Strategi yang digunakan pun

harus berkelanjutan dengan memerhatikan sejumlah variabel ekonomi, sosial, lingkungan dan tata kelola untuk memetakan dan mengetahui persoalan kemiskinan lebih rinci. Fakta tersebut, memerlukan usaha penurunan kemiskinan dengan pendekatan spasial yang dilaksanakan pembuat kebijakan. Kemiskinan perlu dijadikan isu pembangunan lokal secara lokasional dan mempunyai hubungan kuat dengan aspek kewilayahan. Untuk itu, studi ini mengambil fokus yakni, menganalisis keterkaitan kemiskinan secara kewilayahan dan memetakan pola sebaran kemiskinan di seluruh Kabupaten di Indonesia. Harapannya penelitian ini menjadi salah satu acuan pemerintah, sebagai fokuspenanggulangan kemiskinan berdasarkan aspek lokasional, sehingga program-program anti kemiskinan yang dibuat mengikuti karakteristik kewilayahan masing-masing daerah.

\section{METODE PENELITIAN}

\section{Lokasi, Pengumpulan Data, dan Analisis}

Lokasi pemetaan kemiskinan ini adalah Kabupaten di seluruh Indonesia. Pemilihan Kabupaten, karena secara kewilayahan merupakan yurisdiksi dan entitas administrasi pemerintahan terbesar, yakni 80 persen dari total luas wilayah di Indonesia. Kabupaten juga mempunyai Sumberdaya alam (pertanian, perhutanan, minyak bumi dan gas, serta minerba) sebagai sektor-sektor strategis yang dapat dikembangkan dan dijadikan alat untuk keluar dari kemiskinan (keberlanjutan dan inklusifisme). Selain itu Kabupaten memiliki tingkat kemiskinan tertinggi dibandingkan perkotaan.

Seluruh data spasial studi ini dipersiapkan dengan sangat rinci, dimana kedetilan peta pada skala 1:18.000.000. Data spasial ini (peta Indoensia) diperoleh dari Badan Informasi Geospasial (BIG). Studi ini menggunakan data sekunder, yakni persentase kemiskinan di setiap kabupaten dengan periode data tahun 2019. Analisis data yang digunakan untuk mengetahui keterkaitan kemiskinan secara umum di seluruh kabupaten adalah perhitungan Moran Indeks. Sementara untuk memetakan sebaran kemiskinan di masing-masing kabupaten menggunakan pengukuran Local Indicator of Spasial Autocorrelation (LISA). Terakhir penelitian ini juga melihat kebijakan pemerintah pusat dalam menurunkan kemiskinan dengan mengkaji dokumen-dokumen perencanaan pusat.

\section{Analisis Moran Index}

Topler (1979) dalam Lee \& Wong (2001) menyebutkan pada dasarnya semua mempunyai keterkaitan/keterhubungan satu dan yang lainnya, hanya saja sesuatu yang lebih dekat mempunyai keterhubungan erat dibanding yang berjauahan. Landasan ini menjadi acuan untuk melihat efek spasial antarwilayah dengan wilayah lainnya. Igarta \& Handayani (2020) mengemukakan analisis spasial umumnya memerlukan data didasarkan pada lokasi dan kekhasan daerah yang termuat ke dalam tiga (3) ketegori: visualisasi, eksplorasi dan pemodelan. Uji Moran menjadi salah satu tools untuk mengetahui autokorelasi spasial (ketergantungan spasial) antarwilayah amatan yang satu dengan wilayah lainnya (Lee \& Wong, 2001). Singkatnya, karakteristik suatu daerah akan memengaruhi (atau dipengaruhi) karakteristik daerah yang lebih dekat.

Perhitungan Indeks Moran mempelihatkan besarnya ketergantungan daerahdengan daerah lain di sekelilingnya. Formula menghitung Moran Indeks berikut ini: 


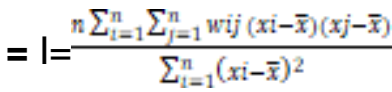

Di mana:

I : Moran's Index

$\mathrm{N} \quad$ : Jumlah wilayah studi (kabupaten)

xi : Nilai pada kabupaten $i$

xj : Nilai pada Kabupaten $j$

wij : Bobot yang terstandarisasi antara kabupaten $i$ dan $j$

Pada tahapan ini hipotesa yang dipakai adalah:

$\mathrm{H}_{0}=\mathrm{I}=\mathrm{I}_{0}$ (Tidak terdapat autokorelasi spasial kemiskinan antarlokasi di setiap kabupaten di Indonesia)

$\mathrm{H}_{\mathrm{a}}=\mathrm{I} \neq \mathrm{I}_{0}$ (Terdapat autokorelasi spasial kemiskinan antarlokasi di setiap Kabupaten di Indonesia)

Sementara nilai ekspektasi Uji Moran sebagai berikut:

$$
\mathrm{E}(I)=I_{0}=\frac{-1}{N-1}
$$

Autokorelasi/keterkaitan terjadi antarlokasi apabila:

$$
Z_{\text {hitung }}=\frac{I-I_{0}}{\sqrt{\text { var }[1]}} \sim N(0,1)
$$

Di mana:

I : Koefisien Moran's Index

Io : Expected value Moran's Index

Var (I) : Varians Moran's Index

Rentang nilai yang diperoleh berdasarkan hasil pengukuran Indeks Moran yakni $-1<\mathrm{I}<1$. Semakin angkanya mendekati satu maka autokorelasi positif semakin kuat, maupun sebalikinya. Penjelasan lebih lengkap sebagai berikut:

- $\quad I_{0}=-1 / \mathrm{n}-1$ mendekati nol (0) (tidak ada autokorelasi/keterkaitan)

- I $>I_{0}$, memiliki keterkaitan positif, membentuk pola data berlompok (clustered)

- $\quad \mathrm{I}<I_{0}$, memiliki keterkaitan negatif dengan pola data menyebar/berpencar (disparead).

\section{Perhitungan Local Indicator of Spatial Autocorrelation (LISA)}

LISA merupakan tools untuk mengidentifikasi dan mengklasterkan kabupaten yang memiliki tingkat keterkaitan (autokorelasi) spasial secara parsial di setiap wilayah amatan. Nilai LISA yang semakin tinggi menandakan wilayah tersebut berdekatan dan hampir sama (membentuk pola penyebaran menggerombol). Perbedaan Moran Index dengan LISA adalah Moran Index digunakan untuk melihat tingkat ketergantungan/keterkaitan secara menyeluruh dalam satu kawasan, sementara LISA digunakan untuk melihat keterkaitan secara parsial dalam satu kawasan. Terdapat beberapa penelitian yang sudah menggunakan perhitungan autokorelasi spasial di antaranya Artino et al., (2019); Harmes et al., (2017); Hasibuan et al., (2019); Okwi et al., (2007); Pratiwi et al., (2013) dalam analisis data kemiskinan. Namun yang menjadi keunggulan penelitian ini adalah menggambarkan atau memetakan kemiskinan di seluruh kabupaten di Indonesia. 
Untuk memetakan dan menganalisis pola kemiskinan menggunakan software GeoDa. Adapun formula LISA sebagai berikut:

$$
\text { Ii }=Z i \sum_{i=1}^{n} W_{i j} Z_{j}
$$

Di mana:

$$
\begin{array}{ll}
l_{i} & : \text { Koefisien LISA } \\
Z_{i} \text { dengan } Z_{j} & : \text { Data telah sudah mengalami standarisasi } \\
\text { Wij } & : \text { Pembobotan antarkabupaten desa } i \text { dan } j
\end{array}
$$

Hipotesis uju parameter LISA

$\mathrm{H}_{0}: \mathrm{I}=0$ (tidak memiliki autokorelasi antarkabupaten)

$\mathrm{H}_{1}: \mathrm{I} \neq 0$ (terdapat autokorelasi antarkabupaten)

Zhukov (2010) memetakan tingkat kemiskinan wilayah yang dibagi menjadi 4 kuadran yakni:

1. high-high): pengelompokan kabupaten kemiskinan tinggi yang dikeliling kabupaten dengan kemiskinan tinggi pula;

2. Kuadran 2, H-L (high-Low): pengelompokan kabupaten kemiskinan tinggi, namun dikelilingi kabupaten yang memiliki kemiskinan rendah;

3. Kuadran 3, L-L (Low-Low): pengelompokan kabupaten kemiskinan rendah dan dikelilingi kabupaten kemiskinan rendah juga; dan

Kuadran 4, L-H (Low-High): pengelompokan kabupaten yang memiliki tingkat kemiskinan rendah, namun dikelilingi kabupaten dengan kemiskinan tinggi.

\section{HASIL DAN PEMBAHASAN}

\section{Kondisi Kemiskinan Tingkat Kabupaten di Indonesia}

Dokumen RPJMN tahun 2020-2024, pemerintah pusat telah mencanangkan penurunan kemiskinan berkisar 7 persen sampai dengan 6,5 persen di tahun 2024. Dengan kata lain, pemerintah menargetkan jumlah penduduk miskin turun sekitar 5,04juta sampai 6,45 juta dalam rentang waktu tahun 2020 sampai tahun 2024. Selain itu pemerintah juga berupaya mengurangi kesenjangan dan menjamin pemerataan ditandai dengan penurunan angka kemiskinan desa menjadi 9,9 persen, penuntasan daerah tertinggal di 25 kabupaten, pengurangan tingkat penduduk miskin di daerah tertinggal menjadi 24 persen yang harus di capai pada tahun 2024 mendatang. Jika melihat dokumen RKP tahun 2021 pemerintah sedang berfokus dalam percepatan pemulihan ekonomi nasional serta reformasi sosial sebagai bagian pencegahan pandemi Covid-19. Tingkat kemiskinan yang tinggi, persentase kelompok rentan (tidak ada jaminan ekonomi) melonjak, berdampak pada ekonomi melambat dan terus resesi hingga minus 3,5 persen. Terdapat beberapa langkah pemerintah dalam mereduksi tingginya kemiskinan, yakni pemulihan industri, pariwisata dan investasi, perbaikan tata kelola kesehatan secaraagregat, perbaikan sistem jaring pengamanan sosial serta ketangguhan terhadap kebencanaan. Sebagaimana yang dikemukakan Kurniawan (2017) peran pemerintah daerah dan pusat sangat diperlukan untuk mengentaskan kemiskinan (memastikan kualitas layanan prima, cepat dan tepat).

Gambar 2 menunjukkan sebaran kemiskinan di seluruh kabupaten di Indonesia. Semakin pekat warna merah menunjukkan semakin tinggi tingkat kemiskinan. Kemiskinan terendah berkisar 1,78 persen (Kab. Badung, Bali) sampai dengan 10,90 persen dan sebagian besar terdapat di Pulau Kalimantan, Pulau Jawa dan sebagian di wilayah Sumatera, terkhusus Provinsi Sumbar dan Riau. Selain itu, data tahun 2020 
menunjukkan pusat-pusat kemiskinan masih terjadi di sebagaian wilayah Jawa Timur,DIY dan Jawa Tengah. Hal ini pun sejalan dengan studi Fahim et al., (2017) mengemukakan kantong-kantong kemiskinan di Pulau Jawa dalam kurun waktu 2011- 2015 terdapat 7 kab/kota dari Provinsi Jawa Barat, Jawa Tengah, DI Yogyakarta danJawa Timur.

Kemiskinan tertinggi sebagian besar berada di bagian timur Indonesia, terutama Pulau Papua dan NTT. Lambatnya penurunan kemiskinan di Provinsi Papua lantaran provinsi ini selalu dijadikan objek pembangunan, otonomi khusus yang diberikan tidak memberikan jaminan pada percepatan pembangunan (Wulansari, 2017). Kabupaten dengan tingkat kemiskinan tertinggi adalah Deiyai $(43,65)$, Intan Jaya $(42,92)$ dan Kabupaten Lanny Jaya $(39,52)$ persen. Selain itu, hampir setiap wilayah kabupaten di provinsi Papua dan Papua Barat termasuk dalam kemiskinan tinggi kecuali Kabupaten Jayapura dan Kabupaten Merauke.

Gambar 1. Sebaran Kemiskinan di Seluruh Kabupaten di Indonesia

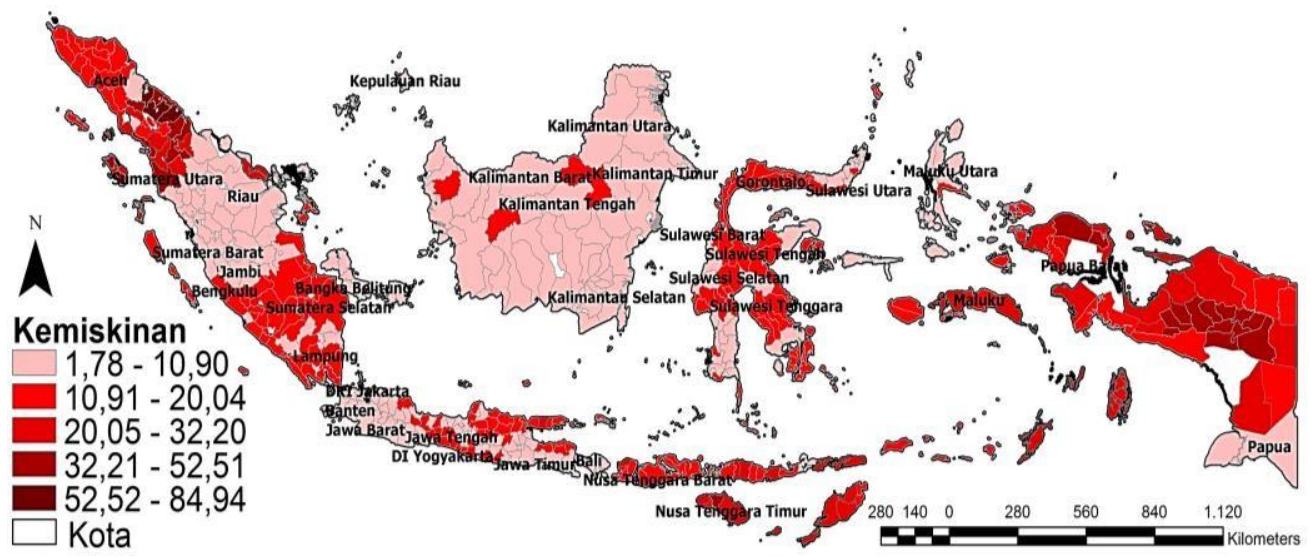

Sumber: BPS, 2021 (data diolah).

Melihat persoalan kemiskinan tidak bisa dilihat dari tingkat kemiskinan saja, melainkan juga aspek kedalaman dan keparahan kemiskinan. Indeks kedalaman kemiskinan (P1) Provinsi Papua mengalami penurunan menjadi 7,17 sedangkan indeks keparahan kemiskinan (P2) mencapai 2,60 poin. Semakin tinggi P1 mengindikasikan semakin sulit menurunkan tingkat kemiskinan di daerah itu, sementara P2 yang tinggi juga memperlihatkan tingkat ketimpangan kemiskinan yang besar (Hasibuan et al., 2019).

BPS (2020) menyebutkan penyebab tingginya kemiskinan di Papua dan Papua Barat adalah: inflasi yang tinggi melebihi inflasi nasional; tingkat pengangguran terbuka yang meningkat $(3,42)$ persen, dan tingginya jumlah konflik yang terjadi. Aksesibilitas yang cukup sulit juga turut menyumbang lambatnya pencegahan kemiskinan.

Hardinandar, (2019); Harianja et al., 2020) mengemukakan dalam mengatasi tingkat kemiskinan di Papua, pemerintah harus berfokus pada perbaikan tingkat pendidikan, agar menghasikan tenaga kerja terdidik, outputnya baik jangka pendek maupun panjang akan memengaruhi perekonomian daerah, disparitas wilayah dan penurunan kemiskinan.

\section{Pola Spasial Kemiskinan (Moran Index) Seluruh Kabupaten di Indonesia}

Cara efektif untuk menurunkan kemiskinan salah satunya dengan mengetahui pola sebaran kemiskinan di setiap kabupaten. Daerah yang memiliki kemiskinan tinggi diduga memiliki keterkaitan dengan daerah lain yang menjadi tetangganya. Salah satu cara 
mengukurnya dengan menggunakan Moran Indeks digunakan melihat dan menganalisis terdapat atau tidak autokorelasi spasial. Moran Index menghasilkan rentang nilai $-1<k<1$. Jika nilai Moran Index mendekati nol, tidak terdapat autokorelasi spasial, jika hasilnya bernilai positif menunjukkan ada autokorelasi spasial bernilai positif dengan pola data menggerombol (clustred) dan jika hasilnya bernilai negative, terdapat autokorelasi spasial negatif dengan sebaran data meyebar (dispread). Hasil pengukuran tingkat kemiskinan 416 Kabupaten di Indonesia dapat dilihat pola penyebaran kemiskinan (Tabel 2) berikut:

Tabel 2. Hasil Pengukuran Moran Index

\begin{tabular}{lr}
\hline Moran's Index $(I)$ & 0,47 \\
Expected Index $(I O)$ & $-0,01$ \\
Variace & 0,01 \\
Z-Score & 7,32 \\
P-value & 0,00 \\
\hline
\end{tabular}

Hasil perhitungan Moran Index memperlihatkan nilai sebesar 0,47 sedangkan nilai expected Index $-0,01$, sehingga terdapat autokorelasi spasial positif dengan sifat yang mengelompok (clustred). Artinya seluruh kabupaten di Indonesia memiliki keterkaitan kemiskinan yang kuat secara umum. Kabupaten yang memiliki kemiskinan tinggi memengaruhi kabupaten-kabupaten yang menjadi tetangganya, begitu sebaliknya. Pola spasial positif seperti ini terbentuk dari kabupaten yang mempunyai tingkat kemiskinan relatif sama dan memiliki jarak yang dekat (bertetangga).

Keterkaitan daerah dilihat berdasarkan adanya titik singgung pada setiap sudut wilayah, dimana titik singgung ini akan menentukan besar/ kecilnya pembobotan spasial. Untuk melihat keterkaitan spasial menggunakan pendekatan metode queen contiquity, yang ditentukan berdasarkan sisi-sisi dan sudut yang bersinggungan yang merupakan tetangga dari wilayah amatan (Wuryandari et al., 2014). Histogram berikut memperlihatkan kabupaten dengan jumlah tetangga terendah sampai dengan jumlahtetangga tertinggi di Indonesia. Jumlah tetangga terendah terdapat 2 wilayah, yakniKabupaten Deiyai dan Intan Jaya di Provinsi Papua, wilayah paling timur Indonesia. Wilayah ini berbatasan langsung dengan Kabupaten Waropen, Puncak, dan Dogiyai.

Gambar 2. Histogram Ketetanggaan menggunakan pendekatan Queen Contiquity Seluruh Kabupaten di Indonesia

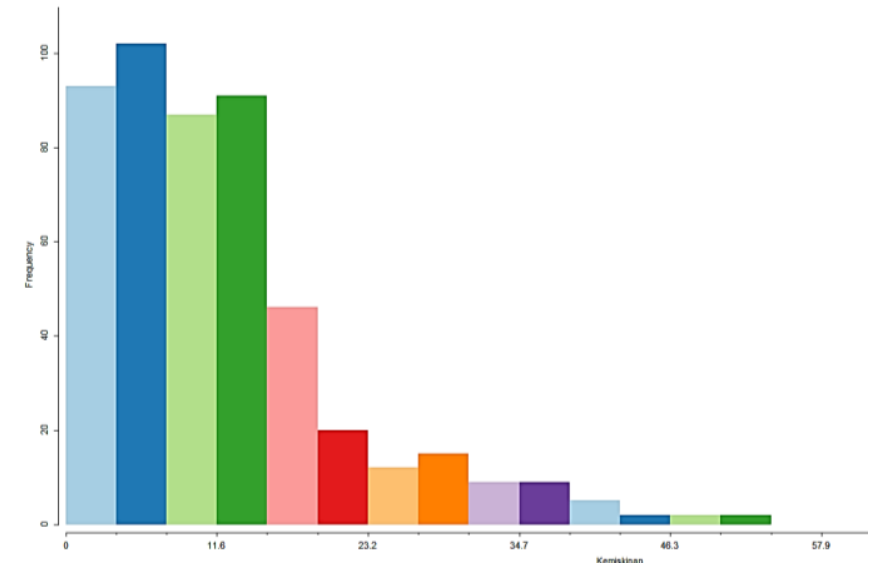


Sumber: Data Diolah, 2021.

\section{Uji Local Indicator of Spatial Autocorrelation (LISA Test)}

Uji LISA mampu melihat terdapat atau tidak ketergantungan spasial lokal secara parsial. Berdasarkan hasil pengolahan data ditemukan terdapat autokorelasi spasial lokal kemiskinan di beberapa kabupaten dan daerah yang lain tidak signifikan. Dari 416 kabupaten di Indonesia yang memiliki autokorelasi spasial lokal sebanyak 136 kabupaten dengan tingkat kepercayaan 99 persen dan 95 persen yang ditunjukkan dengan warna hijau. Dengan kata lain, semakin pekat warna hijau menunjukkan tingkat signifikansi yang semakin tinggi. Pada tingkat signifikansi 0,05 persen, kabupaten yang memilikiautokorelasi spasial lokal tersebar di seluruh Indonesia. Kabupaten pada tingkat signifikansi tersebut di dominasi di Pulau Kalimantan (Provinsi Kalimantan selatan dan Kalimantan Timur) dan Pulau Papua (Provinsi Papua Barat dan Papua). Jika ditilik secaramendalam kabupatenkabupaten yang berada pada tingkat signifikansi 0,05 persen merupakan daerah-daerah yang memiliki kemiskinan rendah (berkisar 1,78-10.90 persen). Sementara kabupaten yang memiliki signifikansi 0,01 kabupaten ini umumnya memiliki tingkat kemiskinan tinggi (berkisar 10,91-52,51 persen).

Gambar 3. Kabupaten yang Mempunyai Autokorelasi Spasila Lokal pada Tingkat kepercayaab 95 dan 99 persen

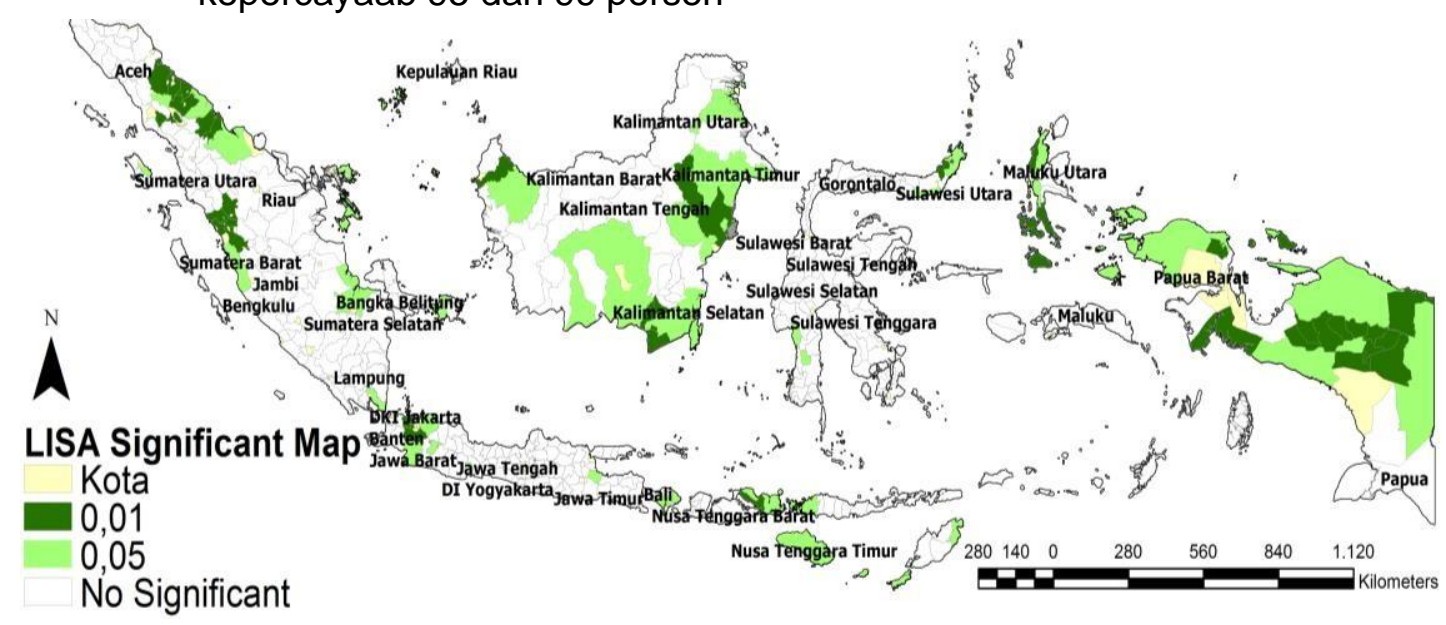

Sumber: Data Diolah, 2021.

Jika mencermati sebaran lokasional pada Gambar 3, autokorelasi spasial kemiskinan lebih dominan di Pulau Sumatera, Kalimantan dan Papua. AdanyaHeterogenitas tingkat kemiskinan pada masing-masing wilayah menunjukkan bahwa program anti kemiskinan pun harus berbeda di setiap wilayah, berdasarkan kekhasanatau karakteristik kabupaten masing-masing. Sebagaimana penelitian Harmes et al., (2017); Hasibuan et al., (2019) menyebutkan adanya autokorelasi spasial lokal di Kabupaten Bandung Barat dan Kota Bengkulu menandakan penanganan harus berbeda pada masing-masing desa dan kelurahan berdasarkan kekhasan wilayah tersebut. Sedangkan daerah-daerah yang tidak signifikan menunjukkan tidak semua kondisi kemiskinan di kabupaten memiliki keterkaitan dengan daerah lain. Keterkaitan hanya akan terjadi jika wilayah-wilayah amatan hampir mirip (mempunyai kesamaan). 
Moran Scatter Plot berfungsi untuk memetakan tingkat kemiripan dan outlier pada data tingkat kemiskinan seluruh kabupaten di Indonesia. Hasil pemetaan kemudian diklasifikasikan ke dalam empat kelompok, yakni Kuadran I (high-high), kuadran II (highLow), kuadran III (low-low) dan Kuadran IV (low-high). Kuadran I merupakan nilai darihasil amatan kabupaten dengan tingkat kemiskinan tinggi diikuti kabupaten dengan persentase kemiskinan tinggi. Kuadran II merupakan kabupaten dengan persentase kemiskinan tinggi, dikelilingi kabupaten dengan tingkat kemiskinan rendah. Kuadran III yakni tingkat kabupaten dengan tingkat kemiskinan rendah, diikuti kabupaten dengan tingkat kemiskinan rendah. Kuadran IV menjelaskan kabupaten yang mempunyai kemiskinan rendah, dikelilingi kabupaten dengan tingkat kemiskinan yang tinggi. Jika dilihat lebih rinci terdapat 50 kabupaten yang berada pada kuadran ke-I, pada kuadran ke-II terdapat 5 (lima) kabupaten, kuadran ke-III 69 kabupaten dan kuadran ke-IV 8 kabupaten. Pemetaan kemiskinan ini memiliki keunggulan, yakni mempermudah pengambil kebijakan untuk mengetahui daerah prioritas dalam menangani kemiskinan. Dengan mengetahui wilayahwilayah prioritas, diharapkan penganganan tingkat kemiskinan tepat sasaran berdasar kantong-kantong kemiskinan di daerah. Adapun daerah-daerah yang masuk ke dalam empat kuadran, dirincikan dalam Tabel 3 berikut.

\section{Tabel 3. Pemetaan Kemiskinan Seluruh Kabupaten di Indonesia}

\begin{tabular}{|c|c|c|c|}
\hline Tinggi-Tinggi (H-H) & $\begin{array}{c}\text { Tinggi } \\
\text { Rendah (H-L) }\end{array}$ & Rendah-Rendah (L-L) & $\begin{array}{c}\text { Rendah- } \\
\text { Tinggi (L-H) }\end{array}$ \\
\hline $\begin{array}{l}\text { Manokwari, Maybrat, } \\
\text { pegunungan Arfak, Raja } \\
\text { Ampat, Sorong, Sorong } \\
\text { Selatan, Tambraw, Biak } \\
\text { Numfor, Boven Digoel, Deiyai, } \\
\text { Dogiyai, Intan Jaya, } \\
\text { Jayawijaya, Keerom, } \\
\text { kepulauan Yapen, Lanny } \\
\text { Jaya, Mambramo Raya, } \\
\text { Mambramo Tengah, Mimika, } \\
\text { Nduga, Paniai, Pegunungan } \\
\text { Bintang, Puncak, Puncak } \\
\text { Jaya, Sarmi, Supiori, Tolikora, } \\
\text { Waripen, Yahukimo, Yalimo, } \\
\text { Belu, Malaka, Manggarai } \\
\text { Barat, Rote Ndao, Sabu } \\
\text { Raijua, Sumba Barat Daya, } \\
\text { Sumba Tengah, Sumba } \\
\text { Timur, Bima, Asahan, Batu } \\
\text { Bara, Deli Serdang, Karo, } \\
\text { Labuhan Batu, Laabuhan Batu } \\
\text { Selatan, Labuhan Batu Utara, } \\
\text { Nias Barat, Serdang Bedagai, } \\
\text { Simalungun }\end{array}$ & $\begin{array}{l}\text { Minahasa } \\
\text { Selatan, } \\
\text { Minahasa } \\
\text { Tenggara, } \\
\text { Kepulauan } \\
\text { Seribu, Lingga, } \\
\text { dan Lampung } \\
\text { Selatan }\end{array}$ & $\begin{array}{l}\text { Soppeng, Pinrang, Bitung, Bolaang } \\
\text { Mangondow Selatan, Minahasa, } \\
\text { Minahasa Utara, Siau Tagulandang } \\
\text { Biar, Halmahera Barat, Halmahera } \\
\text { Utara, Kutai Barat, Kutai } \\
\text { Kertanegara, Kutai Timur, Penajam } \\
\text { Paser Utara, Bulungan, Gunung } \\
\text { Mas, Kapuas, Katingan, Pulang } \\
\text { Pisau, Seruyan, Bnajar, Banjar } \\
\text { Baru, Barito Kuala, Kota Baru, } \\
\text { Tanah Bumbu, Tanah Laut, Tapin, } \\
\text { Bengkayang, Landak, Sanggau, } \\
\text { Badung, Gianyar, Karang Asem, } \\
\text { Tabanan, Tangeran, Tangerang } \\
\text { Selatan, Pasuruan, Bandung Barat, } \\
\text { Bekasi, Bogor, Sukabumi, Agam, } \\
\text { Lima Puluh Kota, Padang } \\
\text { Pariaman, Pesisir Selatan, Solok, } \\
\text { Tanah Datar, Banyuasin, Belitung, } \\
\text { Bintan, Kepulauan Anambas }\end{array}$ & $\begin{array}{l}\text { Kaimana, } \\
\text { Jayapura, } \\
\text { Halmahera } \\
\text { Selatan, } \\
\text { Dompu, } \\
\text { Langkat, } \\
\text { Pakpak } \\
\text { Bharat, } \\
\text { Samosir, } \\
\text { Rokan Hilir }\end{array}$ \\
\hline
\end{tabular}

Kabupaten yang berada pada kuadran I (Tabel 3) merupakan kabupaten dengan kemiskininan tinggi dibandingkan kabupaten lain. Daerah-daerah ini sebagian besar berada di Provinsi Papua, Papua Barat, Sumatera Utara, NTT, dan Nusa Tenggara Barat (NTB). Persoalan pada daerah ini adalah minimnya sarana dan prasarana infrastruktur fisik 
yang menyebabkan terhambat dan lambatnya akses penduduk menjangkau sumbersumber ekonomi. Selain itu akses terhadap pendidikan dan kesehatan juga relatif lebih rendah dibanding dengan provinsi lain (Hatta \& Khoirudin, 2020). Jika kita mengacu data BPS tahun 2020 terdapat peningkatan jumlah penduduk miskin di papua sebesar 0,16 persen. Namun yang perlu diapresiasi adalah pemerintah daerah yang terus berupaya untuk mengentaskan kemiskinan ditandai dengan penerimaan penghargaan Adhi Purna Prima sebagai upaya membentuk masyarakat yang sehat dan berkualitas.

RPJMN tahun 2020-2024 terdapat beberapa strategi untuk pengembangan wilayah (kemiskinan, pengangguran, pemerataan) Papua di antaranya melanjutkan pembangunan/pengembangan infrastruktur fisik sebagai penghubung terhadap titik-titik sentral pertumbuhan dengan pusat-pusat produksi masyarakat; pengembangan industri pengolahan yang tepat guna; mendorong hilirisasi industri; menyiapkan SDM yang terampil dan pengembangan kewirausahaan kaum muda asli Papua; membangun kawasan perkotaan sebagai pusat aglomerasi perkotaan dengan menyediakan akses (perumahan, energi, air minum layak, sanitasi layak, persampahan, drainase, tansportasi umum perkotaan); akselarasi kemudahan dalam layanan perizinan investasi/berusaha dan menjajaki skema kerjasama antardaerah; dan meningkatkan kepastian hukum hak atas tanah (sertifikasi ha katas tanah). Sementara NTT tingkat kemiskinan mengalami peningkatan dibandingkan tahun 2018 yakni naik sebesar 0,06 poin. NTT adalah provinsi dengan tingkat kemiskinan tertinggi, posisi ke-tiga sesudah Papua dan Papua Barat. Terdapat beberapa penyebab meningkatnya tingkat kemiskinan di NTT yakni: hargaproduk pertanian yang menurun, sedangkan harga konsumsi petani meningkat, indeks kenaikan harga meningkat $(0,02$ pesen) dan inflasi di wilayah perdesaan yang meningkat mencapai 2,19 persen. Selain itu tingkat pengangguran terbuka (TPT) mengalami kenaikan 0,09 poin dan ketergantungan masyarakat NTT terhadap komoditas beras. Di daerah perkotaan ketergantungan masyarakat terhadap komoditas beras 28,41 persen berpengaruh terhadap garis kemiskinan sedangkan di perdesaan sebesar 39,14 persen. Artinya jika persediaan beras menipis (tidak cukup tersedia) maka masyarakat NTT akan mengalami tingkat kemiskinan yang cukup parah (florespedia.com, 2019).

Adapun strategi untuk pengembangan wilayah NTT yakni: meminimalkan disparitas masyarakat terhadap aksesibilitas pendidikan dan kesehatan (akselarasi pembangunan manusia); pengembangan kawasan perbatasan dengan Timor Leste; meningkatkan pemberdayaan masyarakat dan persiapan pendidikan keterampilan khususnya pada seluruh sektor strategis; mempercepat pegembangan kawasan perdesaan,3T (tertinggal, terpencil dan terluar) kawasan transmigrasi, serta kawasan perbatasan; mempercepat pengembangan infrastruktur dasar; penyediaan sanitasi, air minum yang layak, persampahan dan perumahan layak bagi masyarakat. Hasil kajian Suparman et al.,(2020) dalam Laporan KPPOD menyebutkan hampir sebagian besar Kabupaten yang terdapat di Papua, Papua Barat, dan Nusa Tenggara memiliki daya saing rendah dan berada pada peringkat terbawah. Rendahnya daya saing daerah ini disebabkan karena minimnya infrastruktur ekonomi (jalan, listrik, internet), pertumbuhan investasi rendah, daya dukung ekonomi wilayah rendah, minimnya Infrastrukur sosial (air minum layak, sarana dan prasarana pendidikan dan kesehatan) serta rendahnya kondusivitaskeamanan (rawan konflik). Kemampuan bersaing yang rendah berdampak pada tingginyatingkat kemiskinan dan pengangguran sebab ketidakmampuan daerah dalam mengoptimalkan faktor input untuk menghasilkan output yang maksimal (daerah berdaya saing). Kabupaten yang masuk kedalam kriteria kemiskinan yang rendah diikuti kabupaten kemiskinan rendah (low-low) sebagian besar berada di Pulau Kalimantan, sumatera dan Jawa (Gambar 5). Pulau Kalimantan merupakan salah satu pulau dengan 
pertumbuhan ekonomi tertinggi yakni 6,4 persen, jika dibandingkan dengan Pulau JawaBali (5,4 persen). Lebih lanjut, Pulau Kalimantan memiliki struktur ekonomi sebagian besar sektor pertambangan (batubara, minyak bumi dan gas dan perkebunan sawit) yang mempengaruhi daya beli masyarakat tinggi. Pengembangan kawasan industri Mempawah di Provinsi Kalimantan Timur turut memberikan dampak baik bagi perekonomian masyarakat setempat.

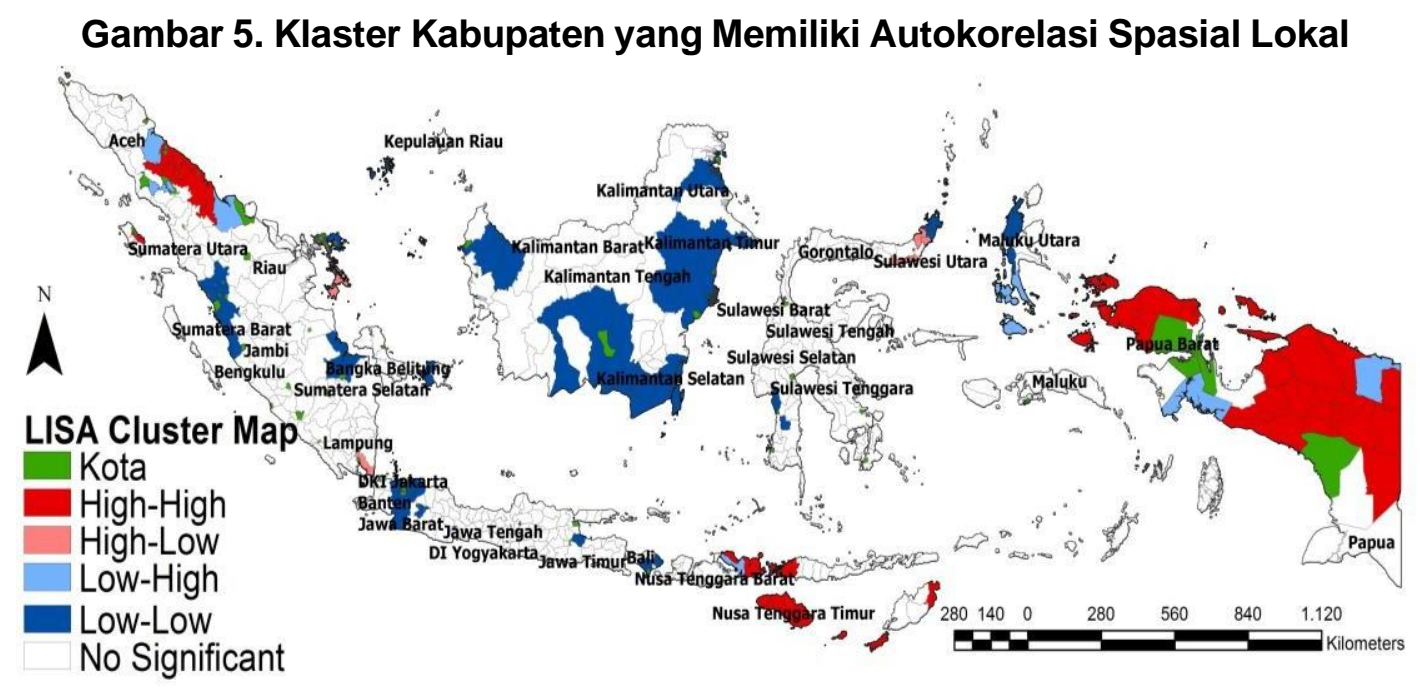

Sumber: Data Diolah, 2021

Pulau Kalimantan juga memiliki peranan sebagai salah satu lumbung energi nasional, Kalimantan telah dicanangkan menjadi ibukota negera tepatnya di Kalimantan Timur. Pemindahan ibukota diharapkan dapat mendorong pemerataan pembangunan dan berdampak positif bagi sektor-sektor yang ada di sekitarnya. Namun tantangan bagi daerah ini adalah bagaimana mempertahankan fungsi ekologis lingkungan untuk meningkatkan daya dukung lingkungan. Kalimantan juga merupakan wilayah yang relatif aman dari ancaman gemba (tidak memiliki gunung api), hanya saja risiko kebakaranhutan dan banjir cukup tinggi. Hal ini pun senada dengan studi Saharjo \& Velicia (2018) yang mengemukakan selalu terjadi kebakaran hutan yang parah hampir setiap tahunnya di Provinsi Kalimantan. Prioritas untuk mendorong pemerataan dan pertumbuhan wilayah 
Kalimantan melalui pemenuhan pelayanan dasar, persiapan infrastruktur dasar, memperlancar konektivitas antarwilayah dan mempercepat pembangunan kawasan tertinggal. Adapun daerah di Pulau Kalimantan yang masuk dalam kategori tertinggal, yakni Kabupaten Bengkayang, Sambas, Kapuas Hulu, Landak, Melawi, Sintang dankayong Utara di Provinsi Kalimantan Barat.

Wilayah lain (tertinggal) terdapat di Provinsi Kalimantan Selatan (Kabupaten Hulu Sungai Utara), Kalimantan Tengah (seruyan), Kalimantan Timur (Mahakam Ulu), dan Kalimantan Utara (Nunukan) (Kemendes PDTT, 2019). Kabupaten yang masuk ke dalam kategori/kriteria kemiskinan yang rendah dikelilingi/diikuti kabupaten kemiskinan tinggi (low-high) sebagian besar terdapat di Provinsi Sumatera Utara, Papua, Papua Barat, dan Maluku Utara (Gambar 5). Kabupaten pada kategori ini layak dijadikan sebagai kabupaten percontohan, karena berhasil keluar

dari kantong-kantong kemiskinan yang menjadi tetangganya. Kabupaten diduga memiliki keunggulan dibandingkan wilayah sekitarnya, sehingga berhasil keluar dari kemiskinan yang tinggi. Kabupaten-kabupaten pada kategori ini juga perlu mendapat perhatian serius, sebab daerah ini masuk dalam kemiskinan rentan. Kabupaten yang berada dalam kategori/kriteria persentase kemiskinan tinggi dikelilingi/diikuti kabupaten dengan tingkat persentase kemiskinan rendah yakni: Provinsi Riau, Lampung, dan Sulawesi Utara (Tabel 3). Selain fokus pada penuntasan daerah-daerah yang merupakan kantong-kantong kemiskinan (high-high) maka daerah ini menjadi prioritas karena tetangganya memiliki kemiskinan rendah. Penyiapan SDM yang terampil menjadi salah satu faktor agar setiap daerah berhasil keluar dari kemiskinan. SDM yang berkualitas sangat membantu masyarakat keluar dari jurang kemiskinan (Sanusi et al., 2014). Pengkategorian ini sejatinya memudahkan pemerintah dalam penanganan kemiskinan. Berdasarkan hasil studi daerah yang berada pada kriteria high-high, low-high dan high-low harus menjadi prioritas. Namun perlu apresisi bagi daerah pada kriteria low-low karena memiliki tingkat kemiskinan yang rendah dibandingkan dengan daerah lainnya. Membangun kerja sama dan pemerataan pembangunan menjadi solusi agar setiap kabupaten bisa keluar dari kemiskinan. Pengembangan potensi lokal, pemanpaatan SDM lokal harus mulai dikembangkan agar roda ekonomi daerah bergerak kearah yang lebih baik.

\section{KESIMPULAN}

Hasil pengukuran menggunakan Moran Indeks menunjukkan terdapat autokorelasi spasial kemiskinan secara umum di seluruh kabupaten dengan pola sebaran yang mengelompok. Artinya kemiskinan yang tinggi pada suatu kabupaten salah satunya dipengaruhi oleh kabupaten disekitarnya yang menjadi tetangganya. Pola spasial positif menunjukkan bahwa kabupaten memiliki tingkat kemiskinan yang relative sama dan memiliki jarak yang dekat (bertetangga). Uji LISA memberikan gambaran hanya 136 kabupaten yang memiliki keterkaitan (pola spasial lokal) yang dipetakan dalam empat kelompok yakni: pertama, terdapat 50 Kabupaten dengan kriteria/ciri kabupaten dengan persentase kemiskinan tinggi dikelilingi kabupaten persentase kemiskinan tinggi (highhigh), kabupaten ini umumnya terletak di Provinsi Papua, Papua Barat, NTT, NTB, dan Sumatera Utara. Kedua, terdapat 69 kabupaten yang masuk dalam kriteria kemiskinan rendah dikelilingi kabupaten kemiskinan rendah (low-low). Kabupaten yang termasukdalam kategori ini terdapat di hampir sebagian besar Palau Kalimantan (Provinsi Kalimantan Timur, Utara, Selatan, Barat, dan Tengah) Jawa Barat, Sumatera Barat Bangka Belitung, dan Maluku Utara. ketiga, terdapat 12 kabupaten dengan kriteria/ciri persentase kemiskinan yang rendah, diikuti kabupaten persentase kemiskinan yang tinggi(Low-high). Kabupaten yang termasuk pada kriteria ini terdapat di Provinsi Sumatera 
Utara, Papua, papua Barat, dan NTB. Keempat, terdapat 5 kabupaten kemiskinan tinggi dikelilingi kabupaten kemiskinan rendah (high-low). Kabupaten yang termasuk dalam kriteria ini terdapat di Provinsi Riau, Lampung, dan Sulawesi Utara.

\section{REFERENSI}

Artino, A., Juanda, B., \& Mulatsih, S. (2019). The Relationship of Village Funds to Poverty. Tataloka, 21(3), 381-389.

Damanhuri, D. (2010). Ekonomi Politik dan Pembangunan: Teori, Kritik, dan Solusi bagi Indonesia dan Negara Sedang Berkembang. Bogor: IPB Press.

Fahim, M., Erfiani, Sartono, B. (2017). Pendeteksian Kantong-kantong Kemiskinan di Pulau Jawa Tahun 2011-2015. Published Tesis. Institut Pertanian Bogor.

Irawadi, A. (2018). Analisis Kemiskinan Spasial dan Kaitannya dengan Sertifikasi Tanah dan Penggunaan Lahan Pertanian di Kabupaten Mamuju. Published Tesis. Institut Pertanian Bogor.

Lee, J. \& Wong D.W.S. (2001). Statistical Analysis ArchView GIS. New York: John Wiley \& Sons, Inc

Gunartin. (2017). Penguatan UMKM Sebagai Pilar Membangun Ekonomi Bangsa. EDUKA Jurnal Pendidikan, Hukum Dan Bisnis, 1(V), 59-74.

Hardinandar, F. (2019). Determinan Kemiskinan (Studi Kasus 29 Kota/Kabupaten Di Provinsi Papua). Jurnal REP (Riset Ekonomi Pembangunan), 4(1), 1-12. https://doi.org/10.31002/rep.v4i1.1337

Harianja, Y., Sahara, \& Muhammad Findi. (2020). Tingkat Kemiskinan Di Pulau Papua Tahun 20011-2017. Jurnal Ekonomi Dan Kebijakan Pembangunan, 7(2), 189-200. https://doi.org/10.29244/jekp.7.2.189-200

Harmes, H., Juanda, B., Rustiadi, E., \& Barus, B. (2017). Pemetaan Efek Spasial pada Data Kemiskinan Kota Bengkulu. Journal of Regional and Rural Development Planning, 1(2), 192-201. https://doi.org/10.29244/jp2wd.2017.1.2.192-201

Hasibuan, Sarah Nita, Juanda, B., \& Mulatsih, S. (2019). Analisis Sebaran Dan Faktor Penyebab Kemiskinan Di Kabupaten Bandung Barat. Jurnal Agribisnis Indonesia, 7(2), 79-91. https://doi.org/10.29244/jai.2019.7.2.79-91

Hatta, R., \& Khoirudin, R. (2020). Analisis Tingkat Kemiskinan di Propinsi NTT: Pendekatan Dua Panel. Jurnal Samudra Ekonomi Dan Bisnis, 11(2), 138-150. https://doi.org/10.33059/jseb.v11i2.2004

Igarta, K. R. R., \& Handayani, F. (2020). Analisis Spasial Sektor Pariwisata di Provinsi Kalimantan Selatan. Jurnal Borneo Administrator, 16(1), 81-100. https://doi.org/10.24258/jba.v16i1.628

Indayani, S., \& Hartono, B. (2020). Analisis Pengangguran dan Pertumbuhan Ekonomi sebagai Akibat Pandemi Covid-19. Jurnal Perspektif, 18(2), 201-208.

Kurniawan, M. (2017). Analisis Faktor-Faktor Penyebab Kemiskinan Di Kabupaten Musi Banyuasin (Studi kasus di Kecamatan Sungai Lilin. Jurnal IImiah Ekonomi Global Masa Kini, 8(01), 16-20.

Masykuroh, D. K., \& Rudiarto, I. (2016). Study on Changes of Land Use And Price In The Ungaran Toll-Gate Area. 18(1), 53-66.

Okwi, P. O., Ndeng'e, G., Kristjanson, P., Arunga, M., Notenbaert, A., Omolo, A., Henninger, N., Benson, T., Kariuki, P., \& Owuor, J. (2007). Spatial determinants of poverty in rural Kenya. Proceedings of the National Academy of Sciences of the United https://doi.org/10.1073/pnas.0611107104

$$
\text { States of America, 104(43), 16769-16774. }
$$

Pratiwi, L. P. S., Srinadi, I. G. A. M., \& Susilawwati, M. (2013). Analisis Kemiskinan 
Dengan Pendekatan Model Regresi Spasial Durbin. Matematika, 2(3), 11-16.

Rustiadi, E., Saefulhakim S., \& Panuju DR. (2008). Perencanaan Pengembangan Wilayah. Bogor: Yayasan Obor Indonesia.

Saharjo, B. H., \& Velicia, W. A. (2018). Peran Curah Hujan Terhadap Penurunan Hotspot Kebakaran Hutan dan Lahan di Empat Provinsi di Indonesia pada Tahun 2015-2016 The Role of Rainfall Towards Forest and Land Fires Hotspot Reduction in Four Districs in Indonesia on 2015-2016. Journal of Tropical Silviculture, 9(1), 24-30. https://doi.org/10.29244/j-siltrop.9.1.24-30

Sanusi, D. K., Kumenaung, A., \& Rotinsulu, D. (2014). Analisis Pengaruh Jumlah Tenaga Kerja, Tingkat Pendidikan, Pengeluaran Pemerintah Pada Pertumbuhan Ekonomi Dan Dampaknya Terhadap Kemiskinan Di Sulawesi Utara Tahun 2001-2010. Jurnal Berkala Ilmiah Efisiensi, 14(2), 120-137.

Suparman, H. N., Mangiri, D., Hasibuan, S. nita, Ramda, eduardo edwin, \& Tambunan, M. (2020). Daya Saing Berkelanjutan Studi Pemeringkatan di 356 kabupaten.

Todaro, M.P. \& Smith S.C. (2011). Pembangunan Ekonomi. Jakarta: Penerbit Erlangga: Edisi Sebelas.

Wulansari, I. (2017). Paradoks Pembangunan Dalam Kemiskinan Strukturan di Papua. Sosiologi Pendidikan Humanis, 2(2), 88-95.

Wuryandari, T., Hoyyi, A., Kusumawardani, D. S., \& Rahmawati, D. (2014). Identifikasi Autokorelasi Spasial Pada Jumlahpengangguran Di Jawa Tengah Menggunakan Indeks Moran. Media Statistika, 7(1), 1-10. https://doi.org/10.14710/medstat.7.1.1-10 